\title{
ALFONSO DE CARTAGENA, HACIA UN VOCABULARIO FILOSÓFICO EN CASTELLANO*
}

\author{
María Díez Yáñez \\ École Normale Supérieure (Lyon) \\ maria.diez-yanez@ens-lyon.fr
}

Leonardo Bruni (1369-1444) en su Isagogicon moralis disciplinae se refería a «la maravillosa fortaleza, virtud por cierto fermosíssima, campo de los oradores», tan estimada por los hombres que comúnmente la vemos representada en las estatuas de los militares, hasta el punto de que «el nombre común de virtud sola fortaleza en su propio apellido ha convertido» ${ }^{1}$.

La labor de Alfonso de Cartagena (1384-1456) le ha transformado en una figura esencial de la mediación cultural hispánica ${ }^{2}$. Así se demuestra también en el tratamiento que hace de la virtud de la fortaleza, que es esencial para el desarrollo de un discurso moral y social castellano. Es conocida su actividad como traductor, trasladador e intérprete de Cicerón, Séneca y Aristóteles ${ }^{3}$.

* Este trabajo se enmarca dentro de las actividades del proyecto Poder, espiritualidad y género: la emergencia de la autoridad femenina en la corte y el convento (Castilla, 1400-1550) (FFI2015-63625C2-1-P). Especialmente se incluye dentro del objetivo «modelos de virtud, saber y poder», que pretende analizar las fuentes clásicas grecolatinas y el discurso cristiano en el desarrollo de un discurso moral y político. Y se publica en colaboración con el proyecto de investigación Alfonso de Cartagena. Obras Completas FFI 2014-55902-P y FFI 2017-84858-P (MINECO y MICINN, Gobierno de España).

${ }^{1}$ «Hinc fortitudo illa mirabilis exstitit, speciosissima profecto virtus, oratorum campus, quae tanto favore hominum excepta est, ut etiam defunctorum statuas videamus fere habitu militari, quasi praeclarum sit hoc potissimum genere laudis in vita claruisse. Commune certe virtutis nomen fortitudo sola in suam propriam appellationem convertit, nec sane immerito, virtus enim a viro dicitur, vir autem constans aliquid et pugnax designare videtur» (Monsterrat Jiménez San Cristóbal, «La versión castellana del Isagogicon moralis disciplinae de Leonardo Bruni conservada en el incunable 1.704 de la Biblioteca Nacional de Madrid», en Cuadernos de Filología Clásica. Estudios Latinos, 22:1 (2002), pp. 87-175, en especial pp. 152-153).

${ }^{2}$ Juan Miguel Valero Moreno, «Alfonso de Cartagena intérprete de Séneca, sobre la clemencia: el presente del pasado», en Atalaya. Revue d'études médiévales romanes, 16 (2016). [En línea] Enlace: <http:// journals.openedition.org/atalaya/1883> [Consulta: 26/03/2018].

3 Traducciones de Cicerón: Libro de Tulio de senectute $=$ De senetute $=$ Libro de la uegez y Libro de Tulio de los ofiçios (1422), dedicadas a Juan Alfonso de Zamora; Rethorica de Tulio M. Cicerón (c. 1424-c. 1431), dedicada al prícipe Don Duarte de Portugal; y Por Marçello (1422-1427) (María Morrás, «Repertorio 
A partir de estos trabajos propongo que analicemos cómo y hasta qué punto sigue Cartagena las tradiciones filosóficas precedentes y cuál es su planteamiento filosófico personal en la materia de la virtud de la fortaleza en aquellas obras en donde selecciona y adapta la Filosofía clásica y la tradición cristiana. De esta manera se podrá analizar con más detalle qué influencia tuvo su producción cultural en la creación de vocabulario filosófico en castellano ${ }^{4}$.

Cicerón en su De Officiis define la fortaleza (fortitudo) como la virtud que lucha por la defensa de la justicia y se refiere a las acciones militares como las que le son más propias. El orador valora también una manifestación cívica de la fortaleza, para la que se pone él mismo como ejemplo según el servicio que presta al estado con su habilidad retórica $(\mathrm{I}, 78)^{5}$. Un aspecto importante de la filosofía estoica es su consideración de las pasiones como impedimento para que la razón humana elija y realice los actos virtuosamente. En esta línea, en su crítica contra los epicúreos, Cicerón les concede que, al menos, hayan logrado salvar de alguna manera una correcta, pero parcial, definición de la fortaleza, al considerarla virtud que desprecia la muerte y soporta (perpétior, per-patior) los dolores (III, 117-118), porque el fuerte «no se espanta por nada, desprecia todo lo humano, no considera insoportable (intolerandum putare) nada que pueda sucederle al hombre» (III, 27).

de obras, mss y documentos de Alfonso de Cartagena (ca. 1384-1456)», en Boletín de la Asociación Hispánica de Literatura Medieval, 5 (1991), pp. 213-248, concretamente pp. 219-222). Traducciones de Séneca: Traducciones de Séneca o de Pseudo-Séneca, de acuerdo a la clasificación de Nicholas G. Round: a) Obras auténticas de Séneca (con sus títulos correctos): Libro primero de la providençia de Dios (De prouidentia I), Libro primero de la clemençia (De clementia I), Libro segundo de la clemençia (De clementia II); b) Obras auténticas de Séneca (con títulos incorrectos): Libro segundo de la providençia de Dios (De constantia sapientis), Libro de la vida bienaventurada (De uita beata y De otio sapientis), Libro de las siete artes liberales (Epistulae morales 88); c) Obras 'pseudo-senequianas': Libro de los remedios contra la fortuna (De remediis fortuitorum), Libro de las quatro virtudes (Martín de Braga, Formula honestae uitae), Amonestamientos e doctrinas (De legalibus institutis, colección de sentencias), Dichos de Séneca en el fecho de la cavallería (extractos de Vegecio, De re militari); d) Obras relacionadas con la Tabulatio de Mannelli: Copilaçión (extensa selección de fragmentos de Mannelli) Libro de las declamaçiones (extractos de Séneca el Viejo, Controuersiae), Títolo de la amistança e del amigo (antología parecida a la Copilaçión), Las tres hermanas virgenes (paráfrasis de De beneficiis) (Tomo esta referencia de Nicholas G. Round, «Alonso de Cartagena's Libros de Séneca: Disentangling the manuscript tradition», en Medieval Spain. Culture, conflict and coexistence. Studies in honour of Angus MacKay, ed. de Roger Collins y Anthony Goodman, New York, Palgrave, 2002, pp. 123-147). Cfr. también Georgina Olivetto, «Alonso de Cartagena y el Humanismo», en Letras, 61-62 (2010), pp. 231-244 y de la misma autora «La collatio externa: en el principio era el códice», en Incipit, 31 (2011), pp. 13-33. Sus obras más relevantes como intérprete de la filosofía moral aristotélica son el Memoriale virtutum (1422) y las epístolas intercambiadas con Leonardo Bruni en las Declamationes super translatione Ethicorum contra Leonardo Aretinum (c. 1430-1433).

${ }^{4}$ Sobre esta idea del desarrollo de un vocabulario filosófico en castellano $c f r$. Carlos Heusch, «La morale du Prince de Viana», en Atalaya. Revue française d'études médiévales hispaniques, 4 (1993), pp. 93-226, y el estudio introductorio de José Luis Villacañas a la traducción de Alfonso de Cartagena, Los cinco libros de Séneca, Murcia, Ediciones Tres Fronteras, 2012.

${ }^{5}$ Cicerón, De Officiis, ed. de Walter Miller, Londres, Heineman, 1913. 
Aristóteles, por su parte, no considera las pasiones como algo siempre moralmente negativo, sino que defiende que hay placeres necesarios y placeres innecesarios, lo mismo que hay placeres y apetitos naturalmente buenos, frente a los que no lo son, porque van contra natura. La razón será la encargada de regular las actuaciones según el término medio. Matiza que la fortaleza regula las tristezas y dolores y que es la templanza o continencia la que tiene por objeto los placeres. En este sentido, además, el Filósofo diferencia el término «dominar» $(\dot{\varepsilon} \gamma \kappa \rho \alpha ́ \tau \varepsilon 1 \alpha)^{6}$, que pertenece a la continencia, del de «resistir» $(\dot{\alpha} v \tau \dot{\varepsilon} \chi \omega)^{7}$, que pertenece a la paciencia $(\kappa \rho \alpha \tau \dot{\varepsilon} \omega)^{8}$, y concluye que, al ser mejor vencer que no ser vencido, el dominio es superior a la resistencia (EN, 1150a33-36) ${ }^{9}$. Santo Tomás de Aquino (1225-1274) en su Summa Theologiae corrobora la postura del Filósofo y rebate las propuestas de san Gregorio, quien se refería a la «fortaleza de los justos que vencen a la carne» $\left(S T, \mathrm{II}^{\mathrm{a}}-\mathrm{II}^{\mathrm{ae}} \text {, q. } 123 \text { a. } 3 \text { arg. } 1\right)^{10}$, y las de Cicerón, quien consideraba propio de la fortaleza «aguantar (pertinere) los peligros y soportar (perpétior) los tra-

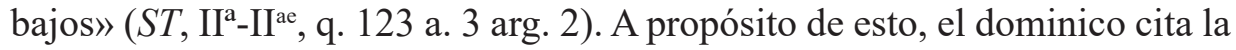
propuesta de san Agustín, a propósito del temor a la muerte, quien señala que la fortaleza «tolera» todo tipo de adversidades, pero porque tiene en mente un bien mayor, el cual, en el caso de san Agustín (y de santo Tomás), es la felicidad celestial (ST, II ${ }^{\mathrm{a}}-\mathrm{II}{ }^{\text {ae }}$, q. 123 a. 4 arg. 1). De hecho, el Filósofo describe la fortaleza como el término medio entre la audacia y el temor, y al fuerte como aquel «que afronta y teme lo que debe y por el motivo debido, cómo y cuándo debe, y confía del mismo modo, es valiente, porque el valiente sufre y obra según las cosas lo merecen y como la razón lo ordena» $(E N, 1115 b 15)$. «Afronta» $(\theta \alpha \rho \rho \varepsilon ı v)$ las cosas penosas ${ }^{11}$, porque persigue un bien más noble que el propio dolor. Pone como ejemplo más claro el de los peligros y dificultades de las batallas bélicas, cuyo objeto es un bien mayor que las supera

${ }^{6}$ Definido como: «mastery over; self-control», en Greek Dictionary Headword Search Results, s. v. $\dot{\varepsilon} \gamma \kappa \rho \alpha ́ \tau \varepsilon 1 \alpha$, ed. de Gregory Cane [Diccionario en línea]. Enlace: <http://www.perseus.tufts.edu/hopper/ resolveform?redirect=true $>$ [Consulta: 10/04/2018]. No traduzco las referencias para evitar confusiones de interpretación.

${ }^{7}$ Definido como: «hold against; hold out against, withstand; hold out, endure» en Gregory Cane (ed.), ob. cit.

${ }^{8}$ Definido como: «Rule; conquer, prevail, get the upper hand; conquer, prevail over» en Gregory Cane (ed.), ob. cit.

${ }^{9}$ Cito a partir de Aristóteles, Ética a Nicómaco, ed. bilingüe y trad. de María Araújo y Julián Marías, $8^{\mathrm{a}}$ ed., Madrid, Centro de Estudios Políticos y Constitucionales, 2002, 1147b4-11478a y 1148a22-1148b.

${ }^{10}$ Tomás de Aquino, Summa Theologiae, en Corpus Thomisticum, ed. de Enrique Alarcón, basada en la ed. Leonina 1969, Pamplona, Fundación Tomás de Aquino. [En línea] Enlace: <http://www.corpustho misticum.org/sth3001.html> [Consulta: 15/03/2018].

${ }^{11}$ Definido como: «to be of good courage; feelconfidence against, have no fear of», Gregory Cane (ed.), ob. cit. 
$(E N, 1115 \mathrm{a} 30)$. En esta línea, Aristóteles, además, critica que la postura estoica defienda que el hombre virtuoso es el que no tiene tristezas, mientras que él considera imposible esa realidad: una cuestión es la imperturbabilidad ante las tristezas $(\dot{\alpha} \tau \alpha \rho \alpha \xi i ́ \alpha)(E N, 1117 \mathrm{a} 3)$ y otra diferente, e imposible, es que nadie tenga dificultades.

Las dos connotaciones atribuidas a la virtud de la fortaleza -resistencia y ataque- deben mucho a la sistematización realizada por santo Tomás de Aquino. En sus Sententia libri Ethicorum traduce el griego vं tir' por sustinere y persistere (lib. 31.18 n. 2) ) $^{12}$ y el griego $\theta \alpha \rho \rho \varepsilon t v$ 'acometer' por aggredire (lib. 3 1. 14 n. 8) ${ }^{13}$. En la Summa Theologiae sistematizará de forma más clara estas dos vertientes de la virtud $\left(S T\right.$, II $^{\mathrm{a}}-\mathrm{II}^{\mathrm{ae}}$, q. 123 a. 3. arg. 6), donde, para subrayar la significación activa de esta virtud, santo Tomás se refiere a aquellos que luchan enfrentándose a los enemigos, pues son fuertes si los agreden y los vencen, y no, como aclara santo Tomás, si los sufren (păť̆or) (Sententia Ethic., lib. 31.16 n. 10) ${ }^{14}$. Respecto a la reacción contra las tristezas, Tomás de Aquino utiliza el término inmutabilitas (Sententia Ethic., lib. 31.14 n. 2) y retoma el argumento aristotélico insistiendo en que la existencia de estas puede servir, incluso, de acicate para el fuerte, que no se arredra ante ellas, sino todo lo contrario (Sententia Ethic., lib. 31.18 n. 9).

Por lo tanto, nos encontramos que, ante en el acto de acometer una acción peligrosa y difícil, una cuestión es «tolerar» las adversidades, otra «sufrirlas» $\mathrm{o}$ «resistirlas» y otra mantenerse «inmutable» ante ellas.

\section{Fortaleza: «esfuerço» o «sufrencia»}

Alfonso de Cartagena en la traducción y paráfrasis de la Ética que presenta en su Memoriale virtutum emplea el mismo término que utilizó santo Tomás para referirse a la resistencia del fuerte:

Fortitudo $[\ldots]$ importat quandam animi firmitatem per quam animus stat inmobilis contra timores periculorum (Memoriale I, 17) ${ }^{15}$.

Dicetur ergo ille fortis qui est intrepidus circa maximum terribile, nullus enim illud melius sustinet quam fortis. [...] pulcrius et virilius sustinebit periculum

12 Tomás de Aquino, Sententia libri Ethicorum, en Corpus Thomisticum, ed. de Enrique Alarcón, basada en la ed. Leonina 1969, Pamplona, Fundación Tomás de Aquino. [En línea] Enlace: <http://www. corpusthomisticum.org/ctc0101.html> [Consulta: 15/03/2018].

${ }_{13}$ Término que encontramos en 42 ocasiones en esta obra.

${ }^{14}$ A propósito de Aristóteles, ob. cit., $1116 \mathrm{~b} 3$.

${ }^{15}$ Los subrayados son míos. Cito por la edición del texto de María Morrás y Jeremy Lawrance (en prensa), a quienes agradezco su generosidad y su perspicacia en las sugerencias y correcciones del presente trabajo. 
et timorem quam alius qui fortis non sit, [...] ut quando aliquis se exponit ad mortem in bello pro fide catholica (Memoriale I-18).

Pero se sirve del término «sofrir» en su traducción del De Officiis, por ejemplo cuando se refiere al que ha de «sofryr tempradamente las bien andanças ${ }^{16}$. En el pasaje latino que remite a este contenido, Cicerón utiliza en su De Officiis el término contemnere 'despreciar', para la ausencia de perturbación (perturbatione liber sis) y para la firmeza, constantia (I, 67). En los casos en que el letrado traduce los pasajes que recogen la resistencia del fuerte a la adversidad, señala que es necesario «menospreciar» con la razón aquellas cosas que parecen grandes y las que son más agrias conviene al hombre «sofrirlas, asy que non te partes del estado de la natura, nin pierdas de la dignidad de sabidor», según compete a aquellos de «rezio coraçon e de gran costançia» ${ }^{17}$, pasaje que va en la misma dirección que el de la necesidad de haber «razón e consideración de menospreciar la muerte e sofrir el dolor e aun la temperanza traen ${ }^{18}$.

En el Oracional (c. 1454), obra dirigida a Fernán Pérez de Guzmán (1376-1458) como respuesta a su petición de consuelo ante sus «presentes tribulaciones $\rangle^{19}$, Cartagena se refiere a una connotación pasiva cuando dice que la «fortaleza dispone al onbre para "constantemente" "tolerar" los peligros e trabajos que en esta vida occuren que son muchos e innumerables» ${ }^{20}$.

La semejanza entre la "sufrencia» y la tolerancia se encuentra en otras obras de autores sobre los que Cartagena tuvo influencia. Así, la referencia

${ }^{16}$ Alfonso de Cartagena, Traducción De Officiis Cicerón, BNM MSS/ 7815, f. 57r. (María Morrás, Edición y estudio de la traducción castellana de De Officiis por Alfonso de Cartagena, Berkeley, Universidad de California, 1990), cito a través de Real Academia Española, Banco de datos (CORDE). Corpus diacrónico del español. [En línea] Enlace: <http://corpus.rae.es/cordenet.html> [Consulta: 2/03/2018]. Un primer testimonio del término «suffrencia» es el Libro de Alexandre. Alonso de Palencia lo define en su Vocabulario como «intollerabile, est lo que sofrir no se puede» y también como «sustentare, sofrir, sostener, comportar». Nebrija sigue la misma línea cuando se refiere a intolerandus, a, um, por cosa de no sufrir y a suffero, $r s$, substuli, por sufrir, tolero por sufrir et padecer. En la versión de 1495 incluye perpetior, eris, por sufrir hasta el cabo» (Lidio Nieto Jiménez y Manuel Alvar Ezquerra, Nuevo Tesoro Lexicográfico del Español (s. XIV-1726), vol. IX, Madrid, Arco/Libros, 2007). Los resultados cuantitativos que arroja el CORDE hablan del dominio del término «sufrir» frente al de «tolerar» en castellano. Los resultados que arroja durante los siglos XII-XV son los siguientes: para «sofrir» o «sufrir», 3014 en 436 documentos y para «tollerar» o «tolerar», 84 casos en 53 documentos, RAE, Banco de datos (CORDE), ed. cit. [Consulta: 3/04/2018].

${ }^{17}$ Alfonso de Cartagena, ob. cit., f. 57r.

${ }^{18}$ Alfonso de Cartagena, ob. cit., f. 143r.

${ }^{19}$ Fernando Gómez Redondo, Historia de la prosa medieval castellana III. Los orígenes del humanismo. El marco cultural de Enrique III y Juan II, Madrid, Cátedra, 2002, p. 3015.

${ }^{20}$ Alfonso de Cartagena, El Oracional, ed. de Silvia González-Quevedo, Valencia, Albatros Hispanófila, 1983, p. 72, cito a través de RAE, Banco de datos (CORDE), ed. cit. [Consulta: 10/03/2018]. 
al sufrimiento pasivo se identifica con la paciencia y con la magnificencia, entendida como parte de la fortaleza, en el Centiloquio (1437) del Marqués de Santillana (1398-1458) cuando dice que esta consiste en «perdonar / e sofrir e tolerar / con pasçiencia» ${ }^{21}$. Otro caso en el que se manifiesta la diferencia entre una connotación activa y pasiva de la fortaleza es en la Suma de la política (1454-1457) de Rodrigo Sánchez de Arévalo (1404-1470) a propósito de los capitanes, que «deben ser acostumbrados en pelear y sufrir muchos trabajos» ${ }^{22}$. En el Vergel de príncipes (1454-1457), por su parte, cita al «Philósopho» en defensa de la actividad física que «face a los omes recios y sofridores $\rangle^{23}$. Un último ejemplo que traigo ahora es el de Pero Díaz de Toledo (1445-1446), en su Glosa a los Proverbios de Séneca (1442-1444), donde recoge el ejemplo de Pericles y Euclides para enseñar que es preciso «soffrir a los que nos persiguen e tolerar benignamente las yras» ${ }^{24}$. Hasta aquí, por lo tanto, comprobamos que la «sufrencia» y la tolerancia se identifican y que se establecen conexiones entre la fortaleza, la magnificencia y la paciencia y el control de la ira. Recordemos que estas obras citadas guardan importantes conexiones con la filosofía estoica y que estas elecciones lingüísticas resultan coherentes con sus desarrollos morales. Veamos ahora, sin embargo, la manera de proceder de Alfonso de Cartagena en la terminología utilizada para la connotación activa de la fortaleza.

En su traducción del De Officiis traduce la definición de fortaleza de la siguiente manera: «bien dizen los estoicos: la fortaleza es peleadora por la igualdad, por ende non ay ninguno que aya alcançado la gloria de fortaleza que aya loor por asechanças e maliçia» ${ }^{25}$. Con el término «peleadora» no solo se remite a una connotación activa, sino también a un ámbito bélico ${ }^{26}$. En el

${ }^{21}$ Íñigo López de Mendoza, Marqués de Santillana, Obras completas, ed. de Ángel Gómez Moreno y Maxim P. A. M. Kerkhof, Barcelona, Planeta, 1988, p. 233.

${ }^{22}$ Rodrigo Sánchez de Arévalo, Suma de la política, ed. de Mario Penna, Madrid, Atlas, 1959, p. 30.

${ }^{23}$ Rodrigo Sánchez de Arévalo, Vergel de príncipes, ed. de Francisco R. de Uhagón, Madrid, Viuda e hijos de Tello, 1900, p. 44, cito a través de RAE, Banco de datos (CORDE), ed. cit. [Consulta: 12/03/2018]. Además, la similitud con la tolerancia se percibe en pasajes referentes a los gustos musicales, cuando advierte que no se pueden «sofrir nin tolerar desvariados e dissonantes cantos», ibidem, p. 74.

${ }^{24}$ Los proverbios con su glosa, ed. facs. de Antonio Pérez y Gómez, y Vicente Soler, Valencia,1965. «...la fonte que mana y corre...». Cfr. también Proverbia vel sententiae [en castellano]= Proverbios, glosados por Pedro Díaz de Toledo (Sevilla, Meinardo Ungut y Estanislao Polono) Madrid, BCUM, BH INC FL-119 [facs. en línea] Enlace: <http://dioscorides.ucm.es/proyecto_digitalizacion/index.php?ir=160\&d $\mathrm{oc}=\mathrm{b} 1911154 \mathrm{x} \& \mathrm{y}=2009>$. Fernando Gómez Redondo aclara al respecto que la mayoría de los proverbios procede de las Sententiae Senecae de Publilius Syrus a la que añade el De moribus de Pseudo-Séneca (Fernando Gómez Redondo, ob. cit., p. 2551, n. 563).

${ }^{25}$ Alfonso de Cartagena, Traducción De Officiis Cicerón, ed. cit., f. 55v.

${ }^{26}$ Remito al verbo «pelear» utilizado líneas arriba por Rodrigo Sánchez de Arévalo, quien también remite a esta connotación activa y bélica cuando menciona el hecho de «acometer cosas terribles» propia de la «fortaleza e nobleza», Rodrigo Sánchez de Arévalo, Vergel de príncipes, ed. cit., pp. 27 y 44. 
Títolo de la amistança, transmite que la fortaleza «acata el apetito o deseo de la ira». Discurso filosófico compatible con la propuesta aristotélica, que había advertido que la fortaleza verdadera no se rige por los accesos de ira $(\theta v \mu o ́ s)$

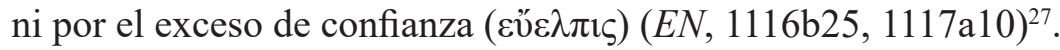

En las obras de carácter moral de entre los contemporáneos de Cartagena, uno de los términos castellanos más utilizados a propósito de la fortaleza es el de «esfuerço». Aparece yuxtapuesto al de «fortaleza» en el Centiloquio de Santillana. Viene acompañado del adjetivo «animoso» y de la propiedad «de gran corazón» en la Suma política de Arévalo, quien, en su Vergel de príncipes, no remite a Aristóteles, sino a Cicerón, cuando se refiere a aquellos que se dedican al ejercicio de la guerra como los que poseen «esmerada fortaleza e esfuerço de coraçon» (27). Más adelante, en el pasaje sobre las bondades del ejercicio físico que antes hemos citado, especifica que esta actividad hace a los hombres «bien dispuestos para los actos de guerra [...] actos de tal fortaleza y valor $[\ldots]$ e faze a los reys, príncipes e grandes varones muy esforçados, e non temerosos de peligros» (44). El significado que se deduce del término «esfuerço», por lo tanto, es el de una disposición activa y valiente, que se enfrenta así a los peligros y cuyo principal campo de acción es la batalla. En otro lugar de su Suma de la política, sin embargo, Arévalo combina el término «esfuerço» con los «osados y de gran audacia» (246), y conviene recordar al respecto que Aristóteles había advertido cómo la audacia era el defecto por exceso de la fortaleza y que aquellos que se dejaban llevar por un ímpetu demasiado «animoso» ( $\varepsilon v ̋ \varepsilon \lambda \pi ı \varsigma$ ) demostraban una falsa fortaleza.

En el caso de Cartagena, sin embargo, no encontramos en las traducciones seleccionadas el uso del término «esfuerzo». Sí aparece, sin embargo, en siete casos en la Qüestión al Marqués de Santillana (1444), refiriéndose a los deberes de los caballeros ${ }^{28}$. Esto podría explicarse en la medida en que esta obra no es un tratado filosófico y que corrobora la selección que caracteriza a Cartagena, la cual, además, no se limita a cuestiones exclusivamente lingüís-

${ }^{27}$ Términos que santo Tomás traduce por el latín iram y (exceso de) spes (Sententia Ethic., lib. 31. 16, n. 1).

${ }^{28}$ «Ca aunque en algunas cosas aquéllos parescan tener mayor estrechura, pero non les manda su orden poner tantas vezes syn algund reguardo su vida en balança nin sofrir algunos syngulares trabajos que el continuo exerçiçio de la esforçada miliçia demanda $[. .]$.$» ; «E este non una mas muchas vezes le$ pasará quien deseare que entre los esforçados cavalleros sea escripto su nonbre»; «Jurarán los cavalleros por Dios e por Nuestro Señor Ihesu Xristo e por el Espíritu Santo e por la magestad del prínçipe, la qual segunt Dios deve ser amada por el linaje humanal, que farán esforçadamente todo lo que el prínçipe les mandare»; «[...] vuestro abuelo e otros grandes con esforçado coraçón fenesçieron sus días»; «[...] e consejo de los cavalleros esforçados e discretos que son en su conpañía»; «mas esto se dize porque quanto quier que alguno sea esforçado, consejando lo muestre al capitán, mas non su mandado ronpiendo» (Alfonso de Cartagena, Respuesta a la Qüestión fecha por el marqués de Santillana, ed. cit., pp. 426-429). 
ticas, sino a la sociales, pues en esta obra el letrado pretende subrayar que la principal actividad propia de un noble caballero consiste en poner sus fuerzas activamente al servicio al reino.

\section{Esfuerzo, fortaleza de ánimo y magnanimidad}

Si acudimos a la definición del término «esfuerço» que nos proporcionan los diccionarios y vocabularios de la época, encontramos que en el Vocabulario de Palencia no aparece y en la entrada para fortitudo leemos la definición de fortaleza física y de fortaleza de ánimo, que remite, a su vez, a la fortaleza y a la magnanimidad. En la entrada correspondiente a animus, expone también los objetos de la magnanimidad y la fortaleza, diciendo que, ante lo venidero es término medio entre la esperanza y el temor, y ante lo sucedido, entre la tristeza y alegría. Por otro lado, en el vocabulario de Nebrija sí hallamos el término «esfuerço», donde se identifica con la fortitudo y el robur animi $^{29}$.

En las obras castellanas se dan multitud de casos en los que el término «esfuerzo» viene combinado con «coraçón», haciéndose así especial hincapié en la característica anímica y no solo física que supone esta virtud. Lo explica expresamente el príncipe de Viana (1421-1461) en su glosa al pasaje 11094 b12 de la Ética, donde remite al «esfuerzo de corazón», en el que expone cuál es la diferencia que existe entre el esfuerzo de corazón y la fortaleza, en la medida en que el primero incluye las cuestiones anímicas y no solo las físicas, demostradas en la capacidad de «tollerar o soffrir» las dificultades:

[...] quise yo, señor muy excelente, dezir a la virtud que el philósopho intitula Fortitudo. Ca bien recolegidos los términos y propiedades [...]. Esta virtud acata acerca el acometimiento y tolerancia de todas aquellas cosas en que hay osadía y miedo [...] y dize que la ferocidad excede en el acometer pero desfallesce en la tollerancia o soffrimiento, y el temor excede en el miedo e intolerancia e fallesce en el acometimiento [...]. Y porque el esfuerço de coraçón faze al hombre acometer y más sufrir, puede ser dicho que el esfuerço es más passiuo que actiuo, quanto quiera que las dos partes possea, y porque vuestra señoría vea la razón que me mouió a scriuir «esfuerzo» y no «fortaleza» como otros han escripto, es porque la virtud que más en esta parte

\footnotetext{
${ }^{29}$ Alonso de Palencia, Universal vocabulario en latín y en romance, Sevilla, Paulus de Colonia cum suis sociis, 1490, ed. facsimilar Madrid, Comisión Permanente de la Asociación de Academias de la Lengua Española, 1967, vol. 1, f. CLXVIIv. [En línea] Enlace: <http://www.cervantesvirtual.com/nd/ ark:/59851/bmc416v3>. Antonio de Nebrija, Vocabulario español-latino, ed. facsímil [Salamanca, 1495?], Madrid, Real Academia Española, 1951, f. LIv. [En línea] Enlace: <http://www.cervantesvirtual. com/nd/ark:/59851/bmcvm466>.
} 
pertenesce solamente a coraçón, y según nuestra lengua, es el esfuerzo y no la fortaleza, la qual, quanto que al ánimo pueda ser atribuyda, más es del cuerpo que del coraçón ${ }^{30}$.

El príncipe de Viana no es, precisamente, un letrado, sino un príncipe que escribe esta traducción y glosa durante su estancia en Nápoles, al no haber sido coronado según su linaje lo exigía. La selección del término, por lo tanto, puede poner en evidencia que no es propiamente una formación filosófica la que sostiene esta obra.

Si volvemos a las fuentes morales clásicas, Cicerón se refiere en su $D e$ officiis a los grandes de ánimo a propósito de la fortaleza ${ }^{31}$. El orador habla de los fuertes y magnánimos (fortes et magnanimi) como aquellos que actúan por la justicia por encima de todo y que no se perturban por los intereses humanos, sino que los desprecian señorialmente (I, 67). Manifiestan su fortaleza cuando soportan con constancia y robustez de ánimo todos los peligros y trabajos que emprenden, porque estos son verdaderamente honestos, hasta el punto de que los consideran superiores a su propia vida (I, 66-67). Como no se podría hablar de verdadera grandeza si no está regida por la justicia, no es propio del fuerte de ánimo dejarse llevar por la avaricia de dinero: no debe ambicionarlo si no lo tiene y debe repartirlo benéfica y liberalmente en el caso contrario. Tampoco es propio de él dejarse llevar por el deseo desordenado de placer (cupiditas), ni por el ansia de gloria (gloriae cupiditas) (I, 68).

Aristóteles no propone el mismo discurso para la magnanimidad

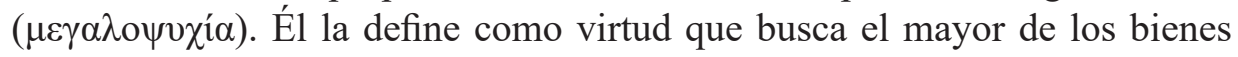
exteriores, el honor, premio de los actos de virtud correspondientes a la gran dignidad de una persona. Esta propuesta aristotélica no resultó fácil de combinar con la más preciada de las virtudes cristianas: la humildad. La peligrosa cercanía entre la magnanimidad y los pecados de la soberbia y el orgullo hacía difícil una aceptación directa ${ }^{32}$. Esto puede ser una de las razones por

${ }^{30}$ Carlos Heusch, art. cit., pp. 112-113. Otra muestra de la falta de firmeza en la terminología se demuestra en la Traducción y glosa a la Eneida de Enrique de Villena (1384-1434), quien se refiere al «esfuerço» como sinónimo de fortaleza (Enrique de Villena, Traducción y glosas de la «Eneida», en Obras completas, ed. de Pedro Cátedra, vols. 2-3, Madrid, Turner, 1994).

${ }^{31}$ «Similis est ratio fortitudinis, quod enim viriliter animoque magno fit, id dignum viro et decorum videtur, quod contra, id ut turpe sic indecorum» (Cicerón, ob. cit., I, 80 y 94). Referencia al decoro que puede relacionarse con el modo de comportamiento adecuado del magnánimo, manifestado en las propiedades que Aristóteles enumera, donde puede ser especialmente reseñable ahora aquella que dice que al magnánimo le caracterizan «movimientos sosegados, voz grave y un modo de hablar reposado» (Aristóteles, ob. cit., 1125a13).

${ }^{32}$ Este tipo de discusiones las encontramos ya en Burley, Buridan y Gerardo de Odón (remito a las notas a la edición del Memoriale de María Morrás y Jeremy Lawrance (en prensa). En la literatura sapiencial pseudo-aristotélica se manifiesta esta necesidad de explicación. Véanse como ejemplos el pasaje 
las que el Marqués de Santillana prefiriera servirse de corrientes estoicas al mencionar la magnificencia y no la magnanimidad en su Centiloquio, como hemos visto arriba. No será la primera vez que se intercambian estos términos en testimonios castellanos ${ }^{33}$. Un ejemplo es el de la Glosa de Pero Díaz de Toledo a los Proverbios de Séneca:

Entre las otras virtudes que Aristótiles pone en el quarto de las Ethicas, es la virtud de la magnificencia e magnanimidad. E lo principal que pone de aquestas virtudes es que non les puede ser fecha injuria ninguna. Ca puesto ge la fagan, el que es magnánimo e magnífico non lo recibe por injuria, antes desdeña al injuriador como a cosa vil e despreciada (Pero Díaz de Toledo, Glosa al Proverbio XXX)

Anteriormente, en la glosa de este mismo autor al Proverbio VII del Marqués y a propósito del «no te pleguen altiveces», había explicado que la soberbia nada tiene que ver con la magnanimidad. Para ello acude a Aristóteles, pero lo parafrasea con la Sagrada Escritura para confirmar que la humildad es contraria a la «poquedad de corazón»y, por lo tanto, compatible con la magnanimidad.

Para comprender este proceso de redefinición o adaptación de los conceptos acudamos de nuevo a las fuentes. Y en este sentido resulta útil el camino que sistematizó santo Tomás de Aquino en relación a las posibles conexiones entre fortaleza, magnificencia y magnanimidad. En su Summa recoge tres propuestas sobre las partes de la fortaleza: la de Cicerón, Macrobio y Andrónico de Rodas. El primero propone las siguientes: «magnificentiam, fiduciam, patientiam et perseverantiam». Macrobio, por su parte, enumera siete: «magnanimitatem, fiduciam, securitatem, magnificentiam, constantiam, tolerantiam, firmitatem»; y Andrónico de Rodas expone otras siete: «eupsychia, lema, magnanimitas, virilitas, perseverantia, magnificentia, andragathia» $\left(S T, \mathrm{II}^{\mathrm{a}}-\mathrm{II}^{\mathrm{ae}}\right.$, q. 128 arg. 1). El dominico critica la opción ciceroniana, argumentando que la confianza no puede ser parte de la fortaleza, sino que lo es

de Poridat de poridades que nos habla de un Aristóteles «humildoso, que temía a Dios» (Secreto de los secretos. Poridat de poridades, ed. de Hugo O. Bizarri, Valencia, Universitat, 2010, p. 100), o en la literatura de consejos de príncipes, el pasaje en el que Juan García de Castrojeriz glosa el De regimine principum de Gil de Roma, explicando la necesaria compatibilidad entre la magnanimidad y la humildad, a pesar de que podría parecer contradictorio en Aristóteles (Juan García de Castrojeriz, Traducción y glosa de De regimine principum de Gil de Roma, Biblioteca del Monasterio de El Escorial, Esc. h.I.8, ff. 100v101r, Libro I, Parte II, Cap. XXV.

${ }^{33}$ Estas identificaciones, sin embargo, son frecuentes en textos que dudosamente se pueden considerar filosóficos o académicos. Véase, por ejemplo, el caso de Enrique de Villena, ob. cit., Libro II, Cap. XVIII, Glosa 420. 
de la esperanza. Además la confianza y la magnificencia no tienen por objeto las acciones peligrosas o difíciles, como sí la fortaleza, por lo que tampoco se pueden incluir como partes de la fortaleza. Además, defiende que la paciencia no es parte de la fortaleza, sino que es la fortaleza misma. Y concluye que la perseverancia no es solo parte de la fortaleza, sino que compete a todas las virtudes. Por último, al ser Cicerón el único de los tres que no incluye la magnanimidad, santo Tomás deduce que la enumeración del orador es incompleta (ST, $\mathrm{II}^{\mathrm{a}}$-II ${ }^{\mathrm{ae}}$, q. 128 arg. 6). El primer argumento tomista resulta coherente con la exposición aristotélica que dice que el fuerte no actúa por la confianza en el éxito, según hemos visto líneas arriba. La identificación de la paciencia con la fortaleza subraya la connotación de resistencia de esta virtud, que Aristóteles no destaca especialmente, pero que es deducida y definida así por el Aquinate. El dominico diferencia la perseverancia de la constancia, diciendo que esta última, y no la primera, forma parte de la fortaleza y, por lo tanto, con la paciencia, al consistir en una permanencia firme ante las dificultades exteriores (ST, $\mathrm{II}^{\mathrm{a}}-\mathrm{II}^{\text {ae }}$, q. 137 a. 3 co.). De todas formas, hemos visto cómo estas tres enumeraciones expuestas por Santo Tomás coinciden en incluir la magnificencia como parte de la fortaleza. Él mismo la incluye en el capítulo dedicado a esta virtud cardinal. Cuando, por el contrario, Aristóteles las diferenció claramente, pues, aunque ambas comparten cuantitativamente la grandeza de sus objetos, cada una tiene objetos diferentes y, por lo tanto, son virtudes distintas.

En su Memoriale Cartagena dedica espacio a la virtud de la magnanimidad en el libro II y deja clara la diferencia que ya expresó Aristóteles, limitando la primera a una virtud exclusiva de los grandes (Memoriale, II, 6). Al respecto, santo Tomás especificaba, con categorías provenientes de un discurso social estamental, que son los «princeps vel privatus nobilis aut ignobilis» los que pueden ser considerados magníficos, aclarando seguidamente que lo son «quod faciant magnos sumptus nobiles genere et gloriosos, puta in honoribus constitutos, et quaecumque similia sunt» (Sententia Ethic., lib. 4 1. 7 n. 6), clasificación social que resulta conveniente para Cartagena, de acuerdo con sus convicciones sobre la organización de la sociedad. Hay un pasaje dedicado a la magnificencia que, sin embargo, habla de la particularidad de Cartagena, quien, aunque en algunos casos sí recorra el camino tomista, no siempre hará el mismo recorrido en otros. Esto ocurre en el momento en que actualiza el texto aristotélico a la hora de poner ejemplos de las expensas magníficas. Mientras el Aquinate especifica la condición pagana del Filósofo, Cartagena obvia esta aclaración, no la considera necesaria, pues la 
magnificencia es compatible con los deberes de un cristiano ${ }^{34}$. Esta solución nos habla, por un lado, de la sensibilidad cívica del letrado, pero también de las distintas finalidades que condicionan los textos: en su Memoriale, Cartagena no pretende cristianizar al filósofo, sino emplearlo para desarrollar la propuesta moral que le exige su determinado contexto.

Además, la magnificencia, en la medida en que se basa en poseer grandes riquezas para emplearlas en grandes acciones, podría considerarse una virtud accesible a toda persona, pues el requisito es poseer bienes suficientes. Otra cuestión, sin embargo, sucede con la magnanimidad: virtud propia de hombres de gran corazón, que actúan conforme a una dignidad superior. A propósito de la superioridad del magnánimo, otra Glosa de Pero Díaz de Toledo dice lo siguiente:

Con el enemigo no se reconcilia ombre seguramente. [Glosa] [...] E entre las otras cosas que pone Aristótiles en el quarto de las Ethicas, de los ombres magnánimos de grand coraçón es cierto que nunca vacan memoria de las injurias e con los ombres que son de aquesta complisión mas segura es la reconciliación que no con los que son de nunca o tarde perdonar ${ }^{35}$.

¿Está queriendo insinuar el letrado que el magnánimo tiene una naturaleza especial al utilizar el término «complisión»? Esto remitiría, entonces, a las corrientes naturalistas que circulaban en la época a propósito de la complexión corporal y sus conexiones con el alma y, por tanto, a las relaciones entre la moral y la phisis ${ }^{36}$. Aristóteles en sus Problemata había hecho mención de las cualidades naturales y su conexión con la moral. A propósito de la teoría de los cuatro humores, Galeno en su De complexionibus decía que la naturaleza equilibrada era la más apta a la virtud. En el contexto de las teorías naturalistas, Pedro d'Avano (1257-1316) destacó al temperamento sanguíneo como el más propenso a la virtud de la fortaleza. Y Aristóteles también propone en su Ética que está más cerca de la virtud el audaz que el cobarde y advertía que eran fuertes aquellos que no se dejaran llevar por la ira $(E N, 1116 \mathrm{~b} 23)$. Por lo tanto, el hecho de que Pero Díaz de Toledo emplee el término «complisión» puede estar advirtiéndonos de que la lectura que hizo de Aristóteles quizá es-

\footnotetext{
${ }_{34}^{34}$ Alfonso de Cartagena, Memoriale, II, 8 y Tomás de Aquino, Sententia Ethic., lib. 4 1. 7 n. 1.

${ }^{35}$ Pero Díaz de Toledo, Proverbia vel sententiae [en castellano], Madrid, BH INC/ FL-119, f. 15r-v.

${ }^{36}$ Matthew Klemm, «Les complexions vertueuses: la physiologie des vertus dans l'anthropologie médicale de Pietro d'Abano», en Médiévales, 63 (2012), pp. 59-74, especialmente p. 67. Según esto, ¿se está refiriendo a la magnanimidad como una naturaleza inherente más que como una virtud adquirida? En ese caso, se estaría separando de la connotación aristotélica (EN, 1115a-1171a) y se estaría acercando a las teorías naturalistas y fisiológicas que defendían una relación dependiente entre la naturaleza corporal y las virtudes.
} 
tuviera influenciada por estas teorías naturalistas, más que por la confianza en la libre elección racional que defiende Aristóteles para toda verdadera virtud.

Volvamos ahora a Cartagena, porque en él encontraremos otra vez una demostración de finura terminológica y filosófica. En su Memoriale dedica siete capítulos a la virtud de la fortaleza, incluida dentro de las virtudes cardinales y la segunda en importancia después de la justicia (I, 17-23). Además el letrado la diferencia expresamente de la magnanimidad:

[...] si timore infamie non cessat ab operacione alicujus boni actus quia per hoc videtur habere quandam firmitudinem animi ['esfuerzo de coraçon'], non tamen proprie in hoc consistit fortitudo, quia istud pertinet ad magnanimitatem, ut in materia sua dicetur (Memoriale I, 17).

La magnanimidad es la virtud no cardinal a la que dedica más espacio, también siete capítulos en el libro II (II,10-16, 7), y la convierte en la virtud central para príncipes y nobles. En su definición y tratamiento de esta virtud se separará del Filósofo a la hora de abordar la compatibilidad entre la magnanimidad y la humildad, pues «licet magnanimus secundum supradicta videtur convenire in aliquibus cum superbo, non tamen est superbus», cuya fuente es Geraldus de Odón y no santo Tomás de Aquino ${ }^{37}$, quien había ya abordado estas explicaciones en su Summa, pero quien también la había complementado exponiéndola como la otra cara de la humildad $\left(S T\right.$, $\mathrm{II}^{\mathrm{a}}-\mathrm{II}^{\mathrm{ae}}$, q. 161, a.1). Cartagena se servirá de los argumentos de la Escritura para explicar la buena convivencia de ambas virtudes, pues no podría servirse únicamente de las aristotélicas, al estar ausentes del programa moral del Filósofo pagano cualquier virtud exclusivamente cristiana.

\section{Magnanimidad y clemencia}

Otra de las propiedades del magnánimo es la de no recordar las injurias recibidas. Cuestión que nos dirige de nuevo a los pasajes citados de Santillana y Pero Díaz de Toledo. El primero identificaba la virtud de la magnificencia con la de la paciencia y, lo que es más interesante ahora, con la capacidad del perdón. En segundo lugar, aunque la clemencia es virtud que no está presente en el esquema aristotélico, Díaz de Toledo cita al Filósofo a propósito de la propiedad del magnánimo, quien no debe tener en cuenta las injurias, porque su dignidad le hace estar por encima de ellas. El glosador matiza que Séneca

\footnotetext{
${ }^{37}$ Anotación de María Morrás y Jeremy Lawrance en su edición del Memoriale virtutum (en prensa).
} 
se está refiriendo a aquellos que no son capaces de perdonar e incluye en el mismo pasaje referencias al Evangelio:

Tus fuerças sientan tus amigos con beneficios tus enemigos con injurias. [Glosa] Dize Tulio en el libro De amicicia: confirma se el amor por el beneficio rescebido. E sant Gregorio dize que la prueva del amor es la honra. E esto es lo que dize que tus fuerças deven sentir tus amigos con beneficios faziéndoles bien e gracia, e non siéndoles cargoso ni enojoso, e dize que los enemigos deven sentir tus fuerças con injurias. Este proverbio no tiene del todo verdad quanto a esta parte, segúnd theología ni philosophía que segúnd Nuestro Salvador nos manda en el Evangelio, devemos amar a nuestros enemigos e fazer bien a aquellos que nos quieren mal e no injuriar los, como dize el proverbio. $\mathrm{Ni}$ así mismo segúnd filosofía debemos injuriar nuestros enemigos que segúnd dize Aristótiles en el IV de las Ethicas el magnánimo que es el virtuoso e de grand coraçón desprecia las injurias que le son fechas e no ha memoria d'ellas. E antes procura a sus enemigos reconciliar los assí con beneficios que no enojando los con injurias ${ }^{38}$.

Además, en su prólogo a las Glosas a los Proverbios del Marqués había enumerado la virtud de la clemencia junto a la de la piedad, liberalidad y misericordia y, sobre todo, haciendo referencia a una naturaleza templada ${ }^{39}$. Más adelante se refiere a la clemencia, citando el De ira, para confirmar que la superioridad del magnánimo se manifiesta en una mesura de espíritu. Una circunstancia histórica puede explicar estas selecciones, pues quizá la insistencia en la magnanimidad y el perdón de las injurias podría estar remitiendo a las desavenencias entre Juan II y don Íñigo López de Mendoza en 1444, ante las cuales, Díaz de Toledo quizá viera conveniente insistir en la conveniencia del perdón, justificándola como demostración de magnanimidad.

Séneca, por su parte, estableció comparaciones entre la justicia y clemencia y las conectó con aquellas existentes entre la magnanimidad y liberali$\mathrm{dad}^{40}$. Pero, propio de una postura estoica, remite también a la mansedumbre

${ }^{38}$ Pero Díaz de Toledo, Proverbia vel sententiae [en castellano], Madrid, BH INC/ FL-119, f. 71r

${ }^{39} «[. .$.$] que sea assí templado a natura que en cobdicia de ninguna avaricia sea travado, mas que se$ muestre en todas cosas liberal e misericorde e piadoso» (Pero Díaz de Toledo, «Prólogo» a su Glosa a los proverbios del Marqués de Santillana). Sobre los datos de las ediciones de esta obra cfr. Georgina Olivetto, «Itinerario de la glosa en los Proverbios del Marqués», en Atalaya. Revue d'études médiévales romanes, 16 (2016). [En línea] Enlace: <http://journals.openedition.org/atalaya/1917> [Consulta: 5/04/2018].

${ }^{40}$ «Pues del mismo modo que no es magnánimo el que es generoso con lo ajeno, sino el que da a los demás lo que se quita a sí mismo, así llamaré clemente no al que se conmueve con el dolor ajeno, sino al que, acosado por los aguijones, no salta; al que entiende que la magnanimidad consiste en sufrir las injusticias cuando está en la cima del poder y que nada hay más glorioso que un soberano a quien 
para los casos en que no se pueda hacer justicia y donde el virtuoso ha de mantener el control sobre sí mismo ${ }^{41}$. Más adelante explica que la clemencia no se identifica con la justicia, sino con la equidad ${ }^{42}$. Este desarrollo poco tiene que ver con la perspectiva aristotélica, quen se referirá a la mansedumbre como la virtud que media entre la ira y un extremo para el que no hay nombre, y que no se relaciona con la justicia y menos con tolerar la injusticia. El Filósofo sí que consideró la epiqueya como virtud superior a la justicia, en cuanto aplica la ley universal $(E N, 1137 \mathrm{~b})$, pero esta afirmación nada tiene que ver con aceptar la injusticia, sino que defiende una forma de aplicar la ley a un nivel superior.

Santo Tomás, por su parte, incluyó la clemencia y la mansedumbre como virtudes propias de la templanza $\left(S T, \mathrm{II}^{\mathrm{a}}-\mathrm{II}^{\mathrm{ae}}\right.$, q. 157). Y a propósito de la justicia, menciona en su Summa Theologicae el código De legibus para confirmar que solo el príncipe puede interpretar la ley correctamente. Sin embargo el Aquinate en esta obra, que es en la que utiliza el término «epieikeia», se centrará en las cuestiones conceptuales de justicia legal, particular y universal.

Veamos qué aportaciones propone Cartagena al respecto. En su traducción de De clementia comienza matizando la terminología de los términos «piedad», «misericordia» y «clemencia», advirtiendo que, aunque tiendan a equipararse en el lenguaje coloquial, conviene diferenciarlos. Para ello, propone una clasificación distinta a la que había expuesto santo Tomás de Aquino: mientras el dominico había considerado la clemencia virtud descendiente de la virtud cardinal de la templanza, y la misericordia como virtud derivada de la virtud teologal de la caridad, el obispo de Burgos dirá que la piedad es un don del Espíritu Santo, mientras la clemencia proviene de la caridad ${ }^{43}$. Por lo tanto, no es virtud cardinal, sino teologal, y tampoco está relacionada con la justicia. En cuanto a la epiqueya, Alfonso de Cartagena, en el capítulo 8 de su Memorial expone que es el término medio de la justicia legal, pues es propio del hombre que posea esta virtud aplicar la justicia en casos en los que

se ofende impunemente» (Séneca, Sobre la clemencia, ed. de Carmen Codoñer, Madrid, Tecnos, 1988, Libro I, p. 42).

${ }^{41}$ «Resulta superfluo en este punto aconsejar que no sea excesivamente crédulo, que arranque la verdad, que proteja la inocencia y sepa que se está tratando de una cosa de interés no menor para el que corre peligro que para el juez: que todo quede claro. En efecto, esto atañe a la justicia, no a la clemencia. Ahora lo estamos animando a que, cuando se le hiera abiertamente, mantenga el control sobre sí mismo y condone la pena, si puede hacerlo sin riesgos. Si no puede, que se modere y sea mucho más comprensivo cuando se trata de las ofensas a él que cuando se trate de una ofensa a otros» (Séneca, ob. cit., Libro I, p. 42).

${ }^{42}$ «Todo esto no es obra del perdón, sino de la clemencia. La clemencia decide libremente. No emite su juicio de acuerdo con fórmulas jurídicas, sino de acuerdo con la equidad y el bien» (Séneca, ob. cit., Libro II, p. 54).

${ }^{43}$ Ana María Montero, «Imagen femenina, virtud y heroísmo: ficción sentimental e historia en Sátira de felice et infelice vida del condestable don Pedro», en eHumanista, 33 (2016), pp. 379-401, esp. p. 388. 
la ley particular no puede hacerlo. Contrario a lo que había hecho santo Tomás en su Summa, Cartagena se detiene con más interés en que esta es virtud frecuentemente vista en los consejos de príncipes, donde el ministro de la ley debe ejercer su servicio. Cartagena está dejando claro, por tanto, que es una virtud cívica, donde la función de consejero de un letrado (como él) es esencial para que el príncipe ponga en práctica la ley equitativamente.

\section{Conclusiones}

A la hora de traducir, Cartagena emplea los términos morales de acuerdo con la escuela filosófica del autor de la obra en cuestión. Sin embargo, en las obras en las que parafrasea o para las que selecciona la teoría moral, los reelabora cuando lo considera oportuno. Aunque utiliza a Aristóteles y a santo Tomás de Aquino, se separará de este en la medida en que sus intereses no son teológicos y adaptará los de aquel a los presupuestos cristianos que le falten y cuando lo considere oportuno. En todas estas decisiones, resulta especialmente destacable la fina distinción entre filosofía, cristianismo y discurso social, y la combinación coherente de acuerdo tanto con el género como con el destinatario de sus trabajos.

En el caso de las virtudes de la justicia y de la clemencia es clara la diferencia que hace entre la connotación espiritual y teológica y la cívica y política: en su discurso expone cómo el príncipe ha de ser justo y dejarse guiar por la epiqueya, pero no menciona la clemencia al respecto. En el caso de la virtud de la fortaleza, Cartagena ha permanecido fiel a los autores estoicos que traduce, pero cuando se trata de su paráfrasis personal, como la del Memoriale, opta personalmente por la diferenciación aristotélica, donde dedica un espacio considerable tanto a la fortaleza (virtud cardinal) como a la magnanimidad (virtud no cardinal) y donde se percibe una insistencia en la vertiente activa de la virtud. Al mismo tiempo hemos visto cómo no emplea el término «sufrencia» ni «tolerancia» más que en el caso particular y explicable del Oracional, ni el de «esfuerzo», exceptuando los pasajes y obras en los que quiere remitir a una fortaleza propia y exclusivamente caballeresca.

Por lo tanto, los motivos de su proceder no se limitan a cuestiones lingüísticas, sino que tienen en cuenta la realidad social a la que sirve y que subyace y se transmite a través de tales selecciones de vocabulario. La misma delicadeza profesional que demuestra al diferenciar la fortaleza de la magnanimidad, la encontramos en el caso de la magnificencia, magnanimidad y clemencia, en donde las preferencias por la opción aristotélica son más evidentes. La primera virtud tiene que ver con las grandes expensas, por lo tanto, todos 
aquellos que tengan bienes suficientes deberían ejercerla. La magnanimidad, como corona de las virtudes, debe ser ejercida por el monarca. Y la clemencia es una cualidad diferente, tanto de la magnificencia, como de la magnanimidad, para la que Cartagena no emplea excesivo espacio, contrariamente a lo que hace con la epiqueya, virtud que requiere de los conocimientos de un letrado que domine la interpretación de la ley para que un rey virtuoso la aplique.

Recibido: $23 / 04 / 2018$

Aceptado: 25/07/2018 


\section{$\cos 8$}

\section{Alfonso De CARTAGENA, HACIA Un VOCABUlario FILOSÓFICO EN CASTELlaNO}

Resumen: El modo de traducción de las fuentes clásicas de Alfonso de Cartagena y su selección y paráfrasis para obras de educación moral, sirven de punto de partida para este trabajo, cuyo objetivo es establecer el papel que ocupa este letrado en la elaboración de un vocabulario filosófico en castellano. Para ello, se comparan sus propuestas lingüísticas acerca de la virtud de la fortaleza con las de aquellos autores contemporáneos e influenciados de alguna manera por él. De esta manera, se pretenden destacar la peculiaridad y finura de la labor de nuestro autor.

Palabras Clave: Traducción. Filosofía. Moral. Fortaleza. Alfonso de Cartagena.

\section{Alfonso de CARTAGENA, towards a PHILOSOPHICAL LEXICON IN CASTILIAN}

ABSTRACT: The starting point of my analysis is the way in which Alfonso de Cartagena selected and translated his Classic sources, as well as the paraphrases he used in his moral works. This study aims to show how Cartagena promoted the creation of a philosophical lexicon in Castilian. I will compare his proposals with those of his contemporaries, who received certain influence from him. This will show the special characteristics and sharpness of Cartagena's work.

KEYwords: Translation. Philosophy. Moral. Fortitude. Alfonso de Cartagena. 